\title{
Comodidad y plaza pública según Vitruvio. Tres ejemplos sevillanos
}

\author{
Alfredo J. Morales *
}

Es sabido que la primera edición española de Vitruvio corresponde a la aparecida en Alcalá de Henares en 1582. Se trata de la traducción efectuada años antes por Miguel de Urrea y para la que su viuda obtuvo el privilegio real en $1569^{\prime}$. Hasta ese momento, los artistas españoles interesados en conocer el texto del arquitecto romano debían acudir necesariamente, a cualquiera de las ediciones italianas, de Fra Giocondo (Venecia 1511), Cesare Cesariano (Como 1521), Giovanni Battista Caporali (Perugia 1536) y Daniele Barbaro (Venecia 1556), o a alguna de las traducciones francesas, como la de Guillermo Philandro (Lyon 1522). Esta circunstancia limitó, sin duda, la repercusión del texto vitruviano a la hora de fundamentar el nuevo estilo renacentista, pues eran pocos los que tenían conocimientos suficientes de alguna de dichas lenguas. Por otra parte, se trataba de obras con escasas ilustraciones. Por ello tuvieron más fortuna otros teóricos del momento, caso de Serlio, cuyos Libros, profusamente ilustrados, permitían la utilización de las imágenes sin preocuparse de la teoría. Así fue, al menos hasta 1552, año de la traducción al castellano de sus Libros III y $\mathrm{N}$, por Francisco de Villalpando, momento a partir del cual resultó más fácil completar y profundizar la información gráfica.

No obstante, a pesar de lo dicho, resulta innegable la importancia de Vitruvio para la arquitectura española del siglo XVI y el hecho de ser el único tratadista cuya autoridad resulta incuestionable. En muchas ocasiones hubo una preocupación clara y decidida por seguir, aún adaptándolos a las necesidades y peculiaridades de cada obra y momento, los principios

* Universidad de Sevilla.

Cervera Vera, Luis, Noticia del De Architectura traducido por Urrea. Madrid 1978. Estudio introductorio a la edición de Vitruvio Pollion, M., De Architectura. Alcalá de Henares 1582, pág. 11. 
expuestos por el arquitecto romano. En otros casos y especialmente en fechas tempranas, se actuó sin tener en cuenta tales presupuestos teóricos, si bien el ambiente intelectual en que se desarrollaron algunos trabajos y la propia formación de ciertos artistas, recogían lejanos ecos de la doctrina vitruviana. Se produjeron así, sin pretenderlo, ciertas relaciones y coincidencias entre los fundamentos teóricos y determinadas plasmaciones arquitectónicas. Sobre algunos ejemplos se trata a continuación.

Hablando Vitruvio en el Capítulo tercero de su primer libro "De las partes de la Architectura en las distribuciones de los edificios públicos", señala que estas son tres. "La una es para defensión, otra para religión, la otra para oportunidad o recreación". Más adelante, tras explicar en que consisten las dos primeras dice: «Distribución de comodidad, es una disposición de lugares públicos» ${ }^{2}$. El mismo texto vitruviano en su libro quinto se dedica a las «disposiciones de los lugares públicos y particulares y lo primero, de que manera convenga ser ordenada la plaza, porque en este lugar se tratan y goviernan las cosas públicas" ${ }^{3}$. La identificación entre "comodidad" y plaza pública, se recogía ya en otros escritos teóricos del renacimiento, caso del Tratado de Arquitectura de Gian Giorgio Trissino o en los comentarios del propio Daniele Barbaro en su traducción de Vitruvio, repitiéndose en ediciones españolas de los Diez Libros realizadas con posterioridad al siglo XVI, como ocurre con la de José Castañeda, publicada en Madrid en $1751^{4}$. Se trata de considerar la plaza como el principal organismo urbano, como el centro vital de la ciudad, resumen o compendio de las actividades cívicas, el cual debe proporcionarse según el número de los pobladores y cuya ordenación y magnificencia están en íntima relación con la importancia y riqueza de la propia ciudad. Estos principios generales llevan aparejados una serie de normas y reglas en

2 Vitruvio Pollion, op. cit., Fol. 11 vto.

Idem, Fol. 66.

"La utilitá adumque, che prepara l'architettura a questo abitare de li omeni, é circa la sicurezza, come é muralie, ponti a simili, o circa la conmoditá, como e piaze..." Trisino Gian Giorgio. “Dell'architettura» en Trattati di architettura. Vol. V. Il Polifilo. Milano 1985, pág. 27. "Defensio moenia, oppida... Religio templa... opportunitas, et conmoditas forum, curiam...» VItruvio Pollionis, M., De architectura libri decem, cum conmentariis Danielis Barbari... Venecia 1567, pág. 24. Castañeda, en el capítulo primero de su edición dice: “Los edificios son o públicos o particulares. Los públicos pertenecen a la seguridad, a la religión o a la comodidad pública. Las fortificaciones de ciudades son para la seguridad, los templos para la religión y las Plazas, Basílicas, Teatros, Academias, para la comodidad pública»... «El tercer género de Edificios Públicos, que sirven para la comodidad y uso del pueblo eran de seis especies, Plazas públicas, Basílicas, Teatros, Puertos, Baños y Academias". Compendio de los diez libros de Arquitectura de Vitruvio. Escrito en Francia por Claudio Perrault de la Real Academia de Ciencias de Paris. Traducido al castellano por D. Joseph Castañeda. Madrid 1751, págs. 95-96 y 107, respectivamente. 
la configuración del espacio destinado a la plaza, perfectamente claras y fáciles de llevar a la práctica cuando se trata de fundaciones o nuevas implantaciones ${ }^{5}$. Pero la materialización de tales ideas resulta más problemática a la hora de actuar sobre un tejido urbano preexistente y básicamente "irracional", como el que caraterizaba las ciudades españolas del quinientos. Se debía ello a la herencia medieval, al reciente pasado musulmán, cuyos testimonios, más que huellas, determinaban, la imagen de la mayoría de las poblaciones españolas. Por eso, el arquetipo clásico sólo pudo plasmarse de manera temporal, gracias al enmascaramiento del mundo urbano real, con las arquitecturas efímeras, o mediante operaciones localizadas, de gran impacto y fuerte carácter emblemático. Así pues, se trataba de acomodar en muchos casos la abigarrada realidad preexistente a las nuevas ideas, introduciendo elementos significativos, con carácter de ruptura, capaces por sí mismos de transformar visual y mentalmente la propia imagen urbana. En tres casos del área sevillana íntimamente relacionados, me centraré en este trabajo.

El primero se refiere a la propia Sevilla, ciudad que conoció a lo largo de la centuria un extraordinario crecimiento, cuyo origen estaba en el monopolio del comercio con el Nuevo Mundo. Producto de ese desarrollo y generalizado enriquecimiento fue la renovación de su caserío, la construcción o profunda remodelación de las sedes de los organismos públicos y la transformación del propio trazado urbano.

Una de las más destacadas operaciones urbanísticas de la primera mitad del siglo xvı fue la desarrollada en la Plaza de San Francisco ${ }^{6}$. Este espacio urbano había sido en tiempos medievales y por su proximidad a la Alcaicería uno de los principales escenarios de la actividad comercial sevillana, lo que ocasionó la concentración en sus alrededores de gran

\footnotetext{
5 Especialmente significativo es el caso de América. Desde los años inmediatos al Descubrimiento puede señalarse una clara intención regularizadora en los nuevos trazados urbanos. Se seguian así diversas instrucciones emanadas de la Corona, finalmente articuladas en las famosas Ordenanzas de Descubrimiento y Población, dadas por Felipe ll en 1573. Sobre el tema es numerosa la bibliografía existente, pudiéndose consultar a modo de resumen, Gutiérrez, Ramón, Arquitectura y urbanismo en Iberoamérica. Madrid 1984. Del mismo autor "Ciudades y pueblos: ocupación espacial y diferencias socioeconómicas", en Historia urbana de lberoamérica. Tomo I. Sevilla 1987 y Catálogo de la exposición La ciudad hispanoamericana. El sueño de un orden. Madrid 1989.

6 Algunos de los aspectos y consideraciones expuestas a continuación fueron adelantados en mi artículo: "La ciudad del Renacimiento", en La arquitectura de nuestra ciudad. Sevilla 1981, págs. 41-45. Sobre dicha plaza puede verse también Alvarez, Lino; Collantes de Terán, Antonio y Zordo, Florencio, cPlazas, Plaza Mayor y espacios de sociabilidad en la Sevilla intramuros", en "Plazas" et sociabilite en Europe et Amerique Latine. Publications de la Casa de Velázquez. París 1982, págs. 90-93.
} 


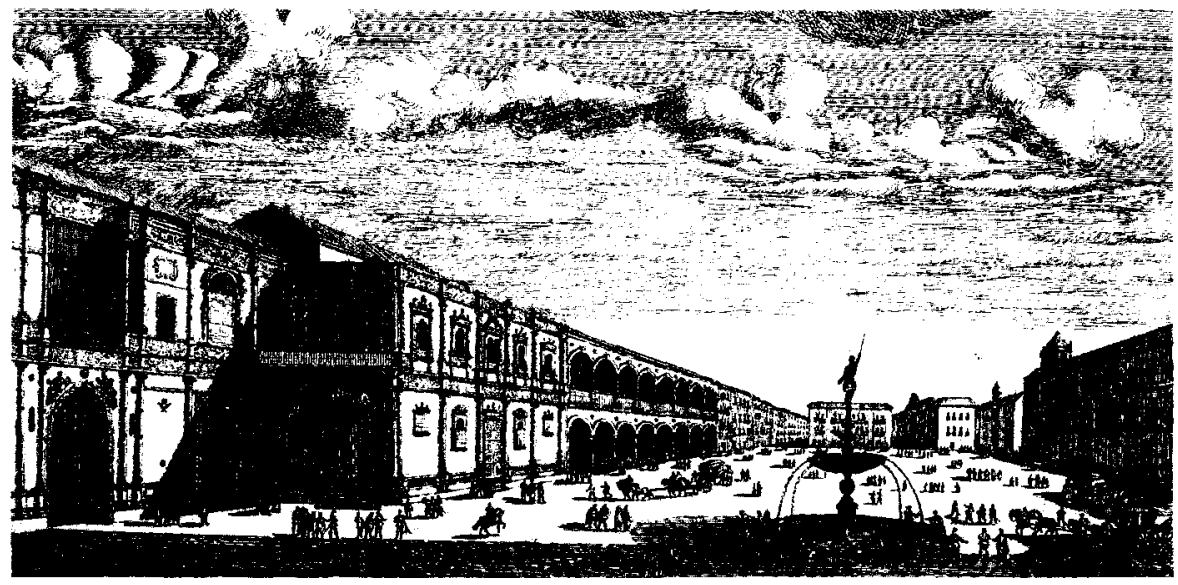

Fig. 1. La Plaza de San Francisco de Sevilla. Louis Meunier. 1668.

número de negocios y pequeñas tiendas. La Plaza de San Francisco tomaba su nombre del convento de dicha advocación, fundado en 1248 , que ocupaba parte del flanco occidental de la misma. En ella se levantaron hasta 1493 unas pescaderías, pero ante las incomodidades y malos olores que originaban se consiguió trasladarlas, liberándose así un importante espacio urbano. Aprovechándose parte del mismo y adosado al monasterio Casa Grande franciscana se edificó el nuevo Ayuntamiento hispalen$\mathrm{se}^{7}$ (fig. 1.)

Hasta ese momento, la sede del cabildo radicaba en el conjunto de edificaciones integrantes del Corral de los Olmos, emplazado entre la catedral y las casas arzobispales. El edificio se compartía con el cabildo de la catedral y presentaba la habitual fisonomía de las construcciones mudéjares $^{8}$. El uso compartido, sus reducidas dimensiones y falta de representatividad plantearon la necesidad de una nueva sede, acorde con la importancia que la ciudad había adquirido trás configurarse como Puerto y Puerta de las Indias. El abandono del Corral de los Olmos y de su

7 Sobre aquel edificio véase Castillo UtRiLla, María José del, El convento de San Francisco. Casa Grande de Sevilla. Sevilla 1988.

\& Al respecto puede consultarse Morales, Alfredo J., La obra renacentista del Ayuntamiento de Sevilla. Sevilla 1981, págs. 13-19. 
entorno, auténtico centro del poder religioso, era además, una prueba del interés de los munícipes sevillanos por manifestar la independencia de su autoridad.

La elección del nuevo emplazamiento era cuestión de enorme trascendencia, puesto que con ello se sentaban las bases para la creación de un nuevo centro cívico. El establecerse en un ámbito urbano amplio, en el borde de una plaza y buscando los efectos escenográficos, es sin duda prueba de una nueva mentalidad a la hora de interpretar la propia ciudad y sus edificios representativos. No obstante, en la decisión pudo actuar como polo de atracción la presencia de otro organismo público establecido desde antiguo en dicho espacio, la Audiencia.

La edificación de las nuevas Casas Capitulares en la Plaza de San Francisco fue el punto inicial de la transformación y nueva valoración de dicho espacio urbano. Las obras se iniciaron en 1526, a los pocos meses de celebrarse en la ciudad la boda del César Carlos con la infanta Isabel de Portugal $^{9}$. Si en aquella ocasión la Sevilla real quedó temporalmente oculta por una ciudad efímera de arcos triunfales, llamativos decorados y colgaduras, ahora se intentaba "petrificar» y hacer permanente el aire clásico de tales tramoyas ${ }^{10}$. El edificio se proyectó así en lenguaje renaciente y cargado de un alto contenido simbólico, como expresión de la nueva imagen que la ciudad pretendía ofrecer de sí misma al mundo. Todo un amplio repertorio de elementos arquitectónicos extraídos "del romano" constituyen la estructura del edificio, sobre la que descansa una selecta iconografía y una vivaz decoración de grutescos. Autor del proyecto e iniciador de las obras fue el arquitecto Diego de Riaño, a quien cabe el honor de ser el introductor del renacimiento en la arquitectura sevillana ${ }^{1}$.

En la actualidad, el aspecto del Ayuntamiento sevillano resulta difícilmente comprensible sin conocer que estuvo adosado al convento franciscano, hoy desaparecido, que a lo largo del siglo xvi se efectuaron diversas obras que alteraron las proporciones y fisonomía de lo proyectado por Riaño $y$, finalmente, que durante los últimos ciento cincuenta

\footnotetext{
9 Véase Carriazo y Arroquia, Juan de Mata, "La boda del Emperador. Notas para una historia del Amor en el Alcázar de Sevilla”, Archivo Hispalense, n. ${ }^{\circ}$ 93-94, 1958.

10 Sobre estas arquitecturas efímeras puede consultarse MORALES, Alfredo J., "Gloria y Honras de Carlos V en Sevilla», en Arquitectura Imperial. Granada 1988.

11 El papel decisivo de este arquitecto en la introducción del léxico clásico lo ne destacado en Morales, Alfredo J., "Tradición y Modernidad, 1526-1563", en Arquitectura del Renacimiento en España, 1488-1599. Madrid 1989, págs. 134 y ss.
} 
años se ha procedido a derribar elementos del edificio primitivo y a incorporar otros nuevos y gratuitos ${ }^{12}$.

Para articular las fachadas de las Casas Capitulares se empleó un orden de pilastras y otro de columnas, estableciéndose así unos módulos, que aun distribuyéndose en distintos ejes, permiten su repetición. A las nítidas líneas verticales de los soportes se contraponen las grandes horizontales de entablamentos y cornisas, estructurándose el conjunto con claridad, gracias al refuerzo plástico que aporta la decoración de grutescos. Todo ello demostrando un profundo conocimiento y dominio de la tectónica clásica, totalmente nuevo en la ciudad. Pero estos muros no sólo marcaron una auténtica revolución en la arquitectura local, sino que también fueron aprovechados para desarrollar un programa erudito y propagandístico.

Como se ha dicho, desde principios del quinientos Sevilla se esforzaba por ofrecer una nueva imagen de sí misma. Su principal afán radicaba en presentarse como heredera de las tradiciones del mundo clásico y como caput imperii. Para ello había sostenido una continua lucha con otra pretendiente, Toledo, a la que había vencido al convertirse en escenario de las bodas imperiales. El triunfo debía ser resaltado, y no sólo por sus implicaciones políticas o económicas, sino fundamentalmente por su potencial «mítico». De hecho, la que se sentía «nueva Roma en ánimo y grandeza» trasladó a los muros del nuevo Ayuntamiento su origen semidivino, la grandeza de sus héroes y el esplendor de un presente feliz. Mediante una serie de medallas, temas heráldicos, representaciones sagradas y profanas, y el complemento de algunas inscripciones latinas, se presenta el Ayuntamiento como Templo de la Justicia y como espejo de la historia ciudadana. Por eso se incluyen, entre otras, imágenes de Hércules, el mítico fundador de la ciudad, de Julio César, el legendario creador y primer presidente de su cabildo, y del emperador Carlos, el nuevo Hércules, quien había devuelto a Sevilla la gloria de sus orígenes. Todo ello sin olvidar a San Fernando, conquistador de la ciudad y eslabón histórico entre los dos momentos claves en la vida ciudadana. Con su hazaña reconquistadora el rey santo la había devuelto a la fe cristiana y la había convertido en cabeza de su reino. Con ello el monarca castellano se había adelantado a la figura del emperador Carlos, quien había logrado la restauración de la ciudad y su conversión en cabeza del imperio, en una operación que era interpretada como una refundación de Sevilla ${ }^{13}$.

12 Un minucioso desarrollo del proceso de transformaciones lo recogí en Morales, Alfredo J., El Ayuntamiento de Sevilla. Arquitectura y simbología. Sevilla 1981.

13 Consúltese Morales, Alfredo J., La obra renacentista..., op. cit., págs. 91-104. 


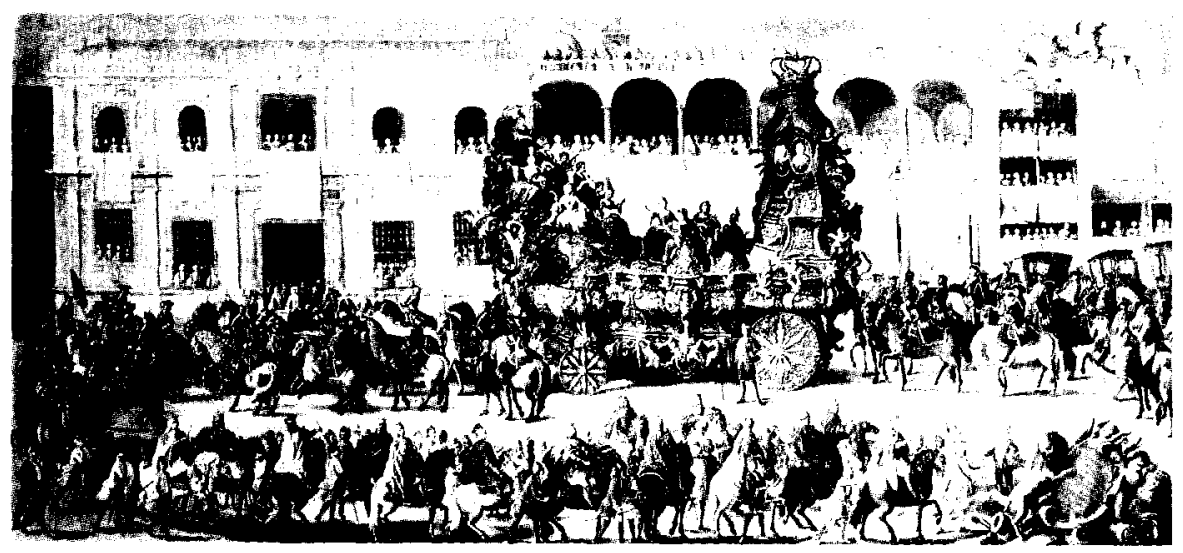

Fig. 2. Máscara de la Fábrica de Tabacos en celebración de la exaltación al trono de Fernando VI. Carro del Parnaso. Domingo Martínez. 1747.

Tan grandilocuente mensaje es prueba del espíritu clásico que alentaba la vida sevillana desde fechas bien tempranas del siglo XVI.

Sucesor de Riaño en la obra del Ayuntamiento fue Juan Sánchez quien, a partir de 1535, se encargó de su ampliación por el flanco meridional, repitiendo la estructuración y fórmulas compositivas del sector primitivo. Se logró así un edificio de cierta uniformidad aunque irregular en su contorno, debido a la configuración del monasterio franciscano preexistente. A este bloque y con un nuevo lenguaje se añadieron, a partir de 1563 , unas galerías porticadas en su costado septentrional. Autor de ellas fue Hernán Ruiz, quien desde tres años antes ocupaba el puesto de maestro mayor de la ciudad. Con esta adición se dotó al cabildo de un excepcional palco desde el que contemplar las fiestas sagradas y profanas, procesiones, autos de fe, corridas de toros, etc. que tenian por escenario dicha plaza (fig. 2.) Ésta se había ya convertido en el centro cívico de la ciudad, habiéndose además enriquecido con una fuente de pila ochavada, inaugurada en 1545 y que debe atribuirse, por razones cronológicas, a Juan Sánchez, maestro mayor del Cabildo, en dicho año ${ }^{14}$. Este elemento no

14 Al parecer la fuente fue concluida coincidiendo con las fiestas celebradas en la ciudad con motivo del nacimiento del príncipe don Carlos. Así se deduce de la información aportada por ORTIZ de ZuÑIGA, Diego, Anales eclesiásticos y seculares de la muy noble y muy leal ciudad de Sevilla. Tomo III. Sevilla 1796, pág. 391. La noticia es también recogida por un anónimo 
sólo ornamental, sino también utilitario, pues abastecía de agua a un importante sector de la ciudad, había sido ya proyectado por Riaño en 1528, cuando se pretendió sustituir el viejo pilar de San Francisco, pero no se llegó a construir ${ }^{15}$. Con la presencia de la fuente, sin duda de aspecto clásico, se transformó visualmente el espacio de la plaza, estableciéndose además un coherente diálogo con las fachadas del nuevo Ayuntamiento.

De las intervenciones hasta aquí analizadas, las correspondientes a Riaño y Sánchez, a pesar de su trascendencia y evidente signo clásico, no puede afirmarse que surgieran con la intención de cumplir el texto vitruviano. Por lo que hasta el momento se conoce de ambos arquitectos, ninguno de ellos poseyó edición alguna de los Diez Libros. Lo contrario ocurre con Hernán Ruiz, quien no sólo poseyó una de las ediciones de Vitruvio sino que llegó a traducir el primero de los libros en su Manuscrito de Arquitectura ${ }^{16}$. Este interés por la tratadistica no se limitó al texto aludido, pues en su biblioteca se incluian, entre otros, Serlio, Alberti y Durero. De ello hay pruebas por el citado Manuscrito y por el testamento del artista en el que dos cláusulas dicen textualmente: «-ytem mando a francisco sanchez mi hermano un libro yntitulado leon baptista Alberto e otro de alberto durero de jumetria e alquitatura. -ytem mando todos mis libros a Hernan Ruiz mi hijo maestro mayor de las obras de la santa yglesia de Cordova y encargo al dicho mi hijo que quando Francisco Sanchez mi hermano a quien tengo mandado dos libros conforme a la clausula antes desta tubiere necesidad de comunicar con el dicho mi hijo algunos libros se los comunique" ${ }^{17}$. Este hecho obliga a preguntarse si la actuación de Hernán Ruiz estuvo influida por el texto vitruviano y, en caso de respuesta afirmativa, a considerar hasta que grado llegó tal influencia. Limitándose a la obra que nos ocupa, las galerías porticadas, cabría establecer cierta relación con lo escrito por Vitruvio sobre la configuración de las plazas por griegos y romanos ${ }^{18}$. Sin embargo, debe recordarse que no se pre-

cronista de la ciudad en el siguiente texto relativo a la celebración del nacimiento del príncipe: "Luego se ordeno que se hiciesen fiestas y regocijos en esta dicha ciudad, y se dieron priesa a hazer los caños para que viniese el agua a una pila nueba ochabada, que se avia acabado en la Plaza de San Francisco, para el dia dela Magdalena, que era el primer dia que avia de aver fiestas en la plaza, y se avian hecho muchos andamios, especialmente el andamio para todo el Regimiento". Anónimo. Memorias eclesiasticas y seculares de la Muy Noble y Muy Leal Ciudad de Sevilla. Copiadas en Sevilla. Año de 1698. Biblioteca Capitular y Colombina. Manuscrito $84-7-19$.

15 Cfr. Morales, Alfredo J., La obra renacentista..., op. cit., pág. 26.

16 Sobre el mismo consúltese Navascues Palacio, Pedro, El libro de arquitectura de Hernán Ruiz el Joven. Madrid 1974.

17 López Martínez, Celestino, Desde Jerónimo Hernández hasta Martínez Montañés. Sevilla 1929, pág. 140

18 Vitruvio Pollion, op. cit., Fol. 66. 


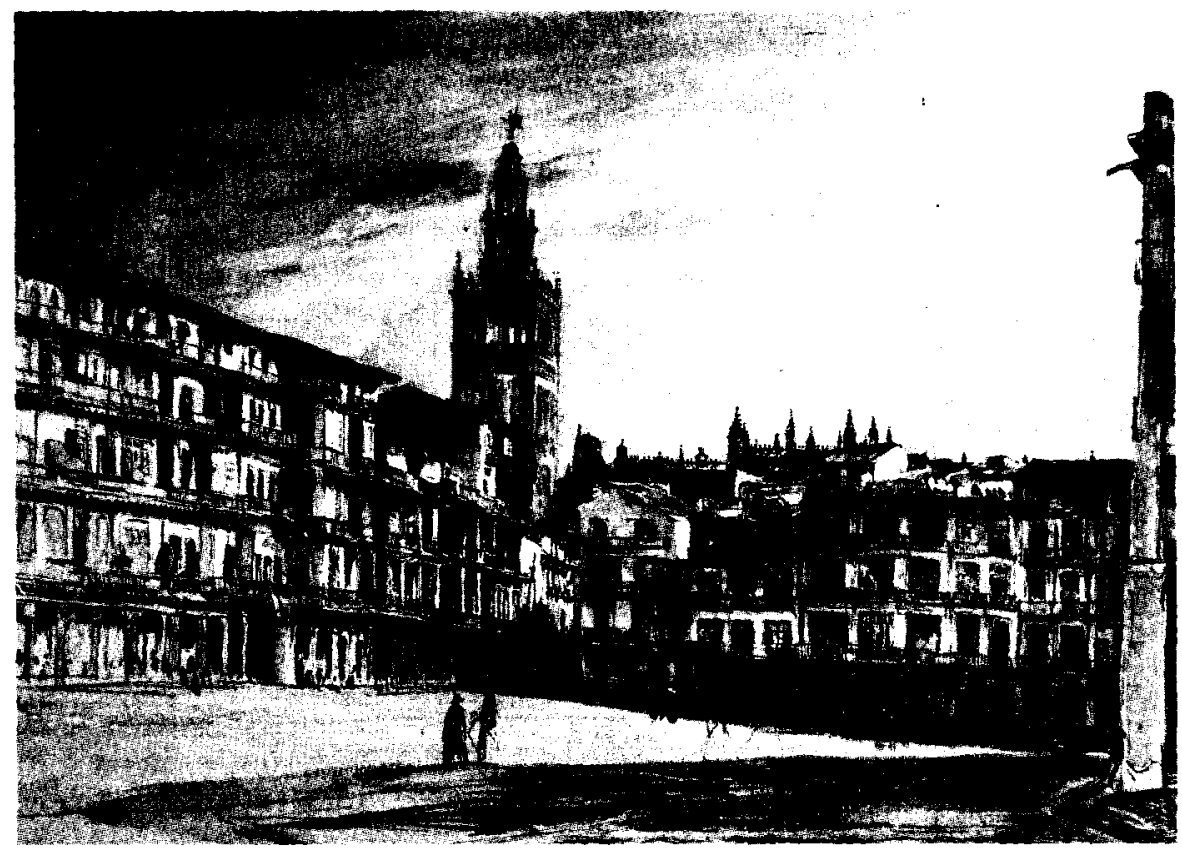

Fig. 3. La plaza de San Francisco, hacia 1833. John Frederick Lewis.

tendía formalizar toda una plaza sino tan sólo dotar a las Casas Capitulares de unos pórticos, elemento habitual en los ayuntamientos hispanos desde época medieval. Por otra parte, hay que tener en cuenta que aquellos ya existían en el flanco oriental de la plaza, pues allí se levantaban una serie de casas cuya planta inferior se retranqueaba para alojar unos soportales. Por cierto que en éstos - curiosa coincidencia con las recomendaciones de Vitruvio-, se ubicaban gran parte de las platerías de la ciudad, agrupadas en un poderoso gremio cuya cofradia de San Eligio tuvo a partir del siglo XVI su sede en el inmediato convento de San Francisco ${ }^{19}$ (fig. 3.)

A la transformación del entorno de la plaza contribuyó también una obra de enorme trascendencia, la ampliación y reforma de la Cárcel Real.

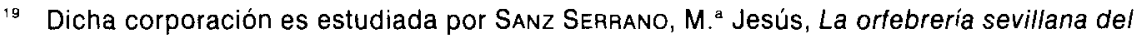
barroco. Tomo I. Sevilla 1976, págs. 25-126. En relación con la capilla del convento franciscano puede consultarse Castillo Utrilla, María José del, op. cit., pág. 81. 


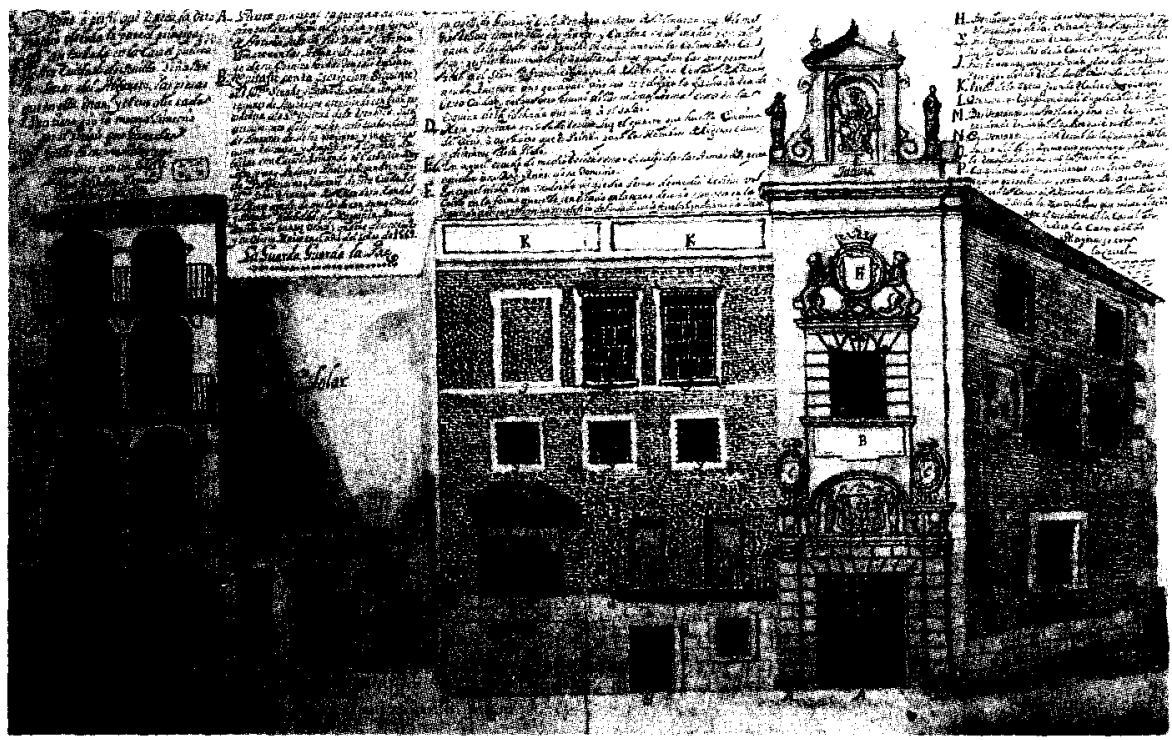

Fig. 4. Fachada de la Cárcel Real de Sevilla, hacia 1700. Juan Navarro.

Ésta, aunque no se ubicaba precisamente en el espacio de la plaza, como aconseja Vitruvio, si constituía el edificio más relevante del flanco septentrional de la misma. El proyecto supuso la adición de nuevas estructuras y la construcción de una monumental portada, a un conjunto de edificios que servía de recinto carcelario desde comienzos del siglo $\mathrm{xv}$. El Cabildo de la ciudad encargó esta obra a Hernán Ruiz en 1569 «atendiendo con gran penitencia a la santa quietud de la República que el atrevimiento de los malos suele turbar'. Los elementos más destacados del programa fueron la creación de una sección destinada a las mujeres y de unas fachadas representativas. De éstas, la principal se abría a la calle Sierpes y contenía la portada, organizada con un orden toscano almohadillado, aunque no rústico, de recuerdos serlianos. En ella se distribuian escudos de armas, carteles con inscripciones y las figuras de la Justicia, Fortaleza y Templaza. Esta portada se realizó tras fallecer Hernán Ruiz por su sucesor como maestro mayor del Ayuntamiento de Sevilla, el arquitecto italiano Benvenuto Tortello ${ }^{20}$ (fig. 4.)

20 Sobre este edificio véase López MARtínez, Celestino, Historia de la Cárcel Real de Sevilla. Madrid 1927. 
La obra de la Cárcel Real introdujo un nuevo elemento clásico en el entorno de la plaza, concretamente en el flanco septentrional. Era preciso actuar en los otros dos frentes para lograr la transformación completa del conjunto. La existencia de gran número de viviendas particulares en ambos lados, limitaba las operaciones. A las primeras se sumaba el edificio de la Señoría de Génova, cerrando el costado meridional. En este, por cierto, ya existía la fuente antes citada, pero al iniciarse el último cuarto del siglo XVI debía aparecer deteriorada, además de resultar inadecuada. Por ello, aprovechando la experiencia de las levantadas con motivo de la creación de la Alameda de Hércules por el conde de Barajas, asistente de la ciudad, se encargó en 1576 a los mismos artífices, el arquitecto Asensio de Maeda, el escultor Diego de Pesquera y el fundidor Bartolomé Morel, la realización de una fuente monumental dedicada a Mercurio. Con su construcción y ubicación en el frente meridional se interpuso un motivo clásico al desordenado conjunto de edificaciones allí existente. Por otra parte, la colocación de dicha fuente en el flanco más ancho de la plaza y descentrada, contribuyó a acentuar el efecto de dilatación espacial originado por la divergencia de las fachadas oriental y occidental del conjunto.

La actuación en el flanco de levante de la plaza, se centró en otro edificio público allí ubicado, coincidiendo con lo recomendado por Vitruvio, la Audiencia. La nueva construcción se desarrolló entre 1595 y 1597, si bien aún se efectuaron algunas labores de escasa entidad en los primeros años del seiscientos. Como autor de la misma se ha considerado al arquitecto Vermondo Resta, que fue maestro mayor de los Reales Alcázares, aunque ahora se duda de la atribución ${ }^{21}$. El edificio ofrecía un zócalo almohadillado sirviendo de asiento a tres plantas de desigual altura y articuladas por pilastras. Al centro se ubicaba la portada y en el ángulo norte un campanario. Su primitiva fisonomía relacionable con otras obras de origen cortesano, caso de la Lonja, sólo se conoce hoy por representaciones y fotografías antiguas, pues sufrió una profunda remodelación entre 1919 y 1924 por el arquitecto Aníbal González ${ }^{22}$.

Todas estas puntuales y dispares intervenciones en el espacio de la plaza o en sus inmediaciones, contribuyeron a dotarla de una peculiar imagen clásica. Por otra parte, la propia irregularidad de la plaza, a la vez que disimulaba la heterogeneidad de sus elementos constitutivos, fa-

21 Cfr. Marín Fidalgo, Ana, Vermondo Resta. Sevilla 1988, pág. 123.

22 Véase VILlar MOVellán, Alberto, Arquitectura del regionalismo en Sevilla (1900-1935). Sevilla 1979, págs. 307-308. 
vorecía su visión en perspectiva ${ }^{23}$. Pese a todo, el centro cívico de la que decía ser la Nueva Roma se configuró según el nuevo estilo.

Estrechamente vinculado al proceso de creación y transformación del nuevo centro cívico de Sevilla se encuentra el de dos poblaciones serranas, hoy onubenses pero antaño integradas en el reino sevillano, Aracena y Zufre. Ambas desempeñaron un papel decisivo durante la época medieval en el sistema defensivo de la capital andaluza, dada su proximidad a la siempre conflictiva frontera portuguesa ${ }^{24}$. El estar administrativa y religiosamente bajo la jurisdicción de la ciudad de Sevilla conllevaba su dependencia artística, de tal manera que aquella actuó de centro y éstas de periferia. Con evidente afán mimético se procuró plasmar en ambas poblaciones el modelo sevillano, aunque reduciendo la escala y la envergadura de las obras. De llevarlo a cabo se encargó al arquitecto Hernán Ruiz II, a quien su trabajos como maestro mayor del arzobispado hispalense obligaron a visitar y dirigir las obras de las iglesias parroquiales de dichas localidades, aprovechándose entonces su presencia para encomendarle la configuración de los respectivos centros urbanos. En ellos pudo ampliar el arquitecto sus experiencias sevillanas, especialmente las relativas a la Plaza de San Francisco.

En Aracena fue determinante la construcción de la nueva parroquia de la Asunción para la creación del nuevo centro cívico. De hecho, la población había estado asentada en torno al castillo ubicado sobre un cerro y al que se adosaba la iglesia parroquial. El espacio constituyó durante siglos el núcleo de la villa. Pero al irse desplazando sus habitantes hacia zonas más cómodas y bajas, aquel se fue quedando aislado, haciéndose necesaria una nueva parroquia. Ésta se proyectó aislada, con grandes proporciones y sobre un terreno previamente allanado. En su construcción intervinieron Diego de Riaño y Juan de Calona datándose la presencia de Ruiz el Joven a partir de 1562, año de su nombramiento como maestro mayor del arzobispado sevillano. El templo se proyectó con extraordinaria monumentalidad, razón por la cual nunca se concluyó. Debía contar con tres naves de cinco tramos, si bien sólo se edificaron los dos primeros, además del conjunto de dependencias de la cabecera. Con el maestro hay que relacionar algunos abovedamientos, así como los capiteles del

23 Morales, Alfredo J., La ciudad del..., op. cit. págs. 44-45.

24 Al respecto puede consultarse PÉREZ-EMBID, Florentino, La frontera entre los reinos de Sevilla y Portugal. Sevilla 1975. En relación con dichas poblaciones es oportuno recordar que sus respectivos castillos pertenecian al Ayuntamiento de Sevilla. Véase MoRALES, Alfredo J., Arquitectura medieval en la Sierra de Aracena. Sevilla 1976, págs. 59-62, 73 y 74. 
primer tramo y los soportes del último, constituidos por pilares cuadrados a los que se adosan medias columnas toscanas.

Frontera a la iglesia, aprovechando unas construcciones medievales preexistentes y en acusado desnivel, se emplazó el Ayuntamiento, que servía también de Cárcel y de Pósito. El proyecto de Hernán Ruiz no resulta hoy muy comprensible, pues han desaparecido algunos elementos básicos del mismo, como son los pórticos que enlazaban varias edificaciones. No obstante, parece claro que existió un interés por homogeneizar todo el edificio municipal, en el que destacan su portada principal, una ventana y los fragmentos de la galería porticada, que aparecen cegados. Ésta se formaba con arcos enmarcados por alfiz y apeados en pilares de ladrillos, material del que se hizo una portada secundaria. Por su parte, la principal y la ventana bífora citada están ejecutadas en piedra caliza, pero mientras la segunda se encuadra en la tradición medieval, aquella es de formulación clásica. En ella se repite un esquema habitual en el maestro, constituido por columnas toscanas sobre pedestales, soportando un frontón de triple curvatura. Sobre un vano adintelado, una inscripción latina, tomada del salmo 85, ocupa el friso y data la construcción en $1563^{25}$. Dicha leyenda demuestra que el edificio fue concebido como Templo de la Justicia, idea desarrollada en otros muchos ayuntamientos españoles del quinientos, pero que aquí parece derivar directamente del Cabildo sevillano (fig. 5).

Una operación urbanística similar pero completada con la construcción de un pilar, según una fórmula muy repetida en los procesos de renovación urbana del renacimiento, se desarrolló en Zutre. Las transformaciones se iniciaron con la remodelación de la parroquia de Santa María. El viejo templo medieval, del que sólo se conservó el hastial gótico-mudéjar, fue reconstruido a lo largo del siglo XVI, habiendo intervenido en las obras Hernán Ruiz II. Con su actuación se relaciona el cerramiento de la capilla mayor en 1563, la construcción de las ventanas y bóvedas de la nave, una de las cuales va fechada en 1568.

Coincidiendo con estas obras, frente al templo, en el que aún se trabajaba después de fallecer el maestro, se levantó el Cabildo, habiéndose aprovechado el desnivel del terreno para disponerlo sobre un alto podio. El edificio se construyó de cantería, ofreciendo su fachada principal dos plantas porticadas. La inferior, más esbelta, presenta tres arcos de medio punto enmarcados por alfiz. En la superior se han usado arcos carpaneles,

${ }^{25}$ La inscripción dice "Veritas de terra orta est et iustitia de celo proxpexit". Cuya traducción es "Brota de la tierra la fidelidad y mira la justicia desde lo alto de los cielos». Salmo 85,12 . 


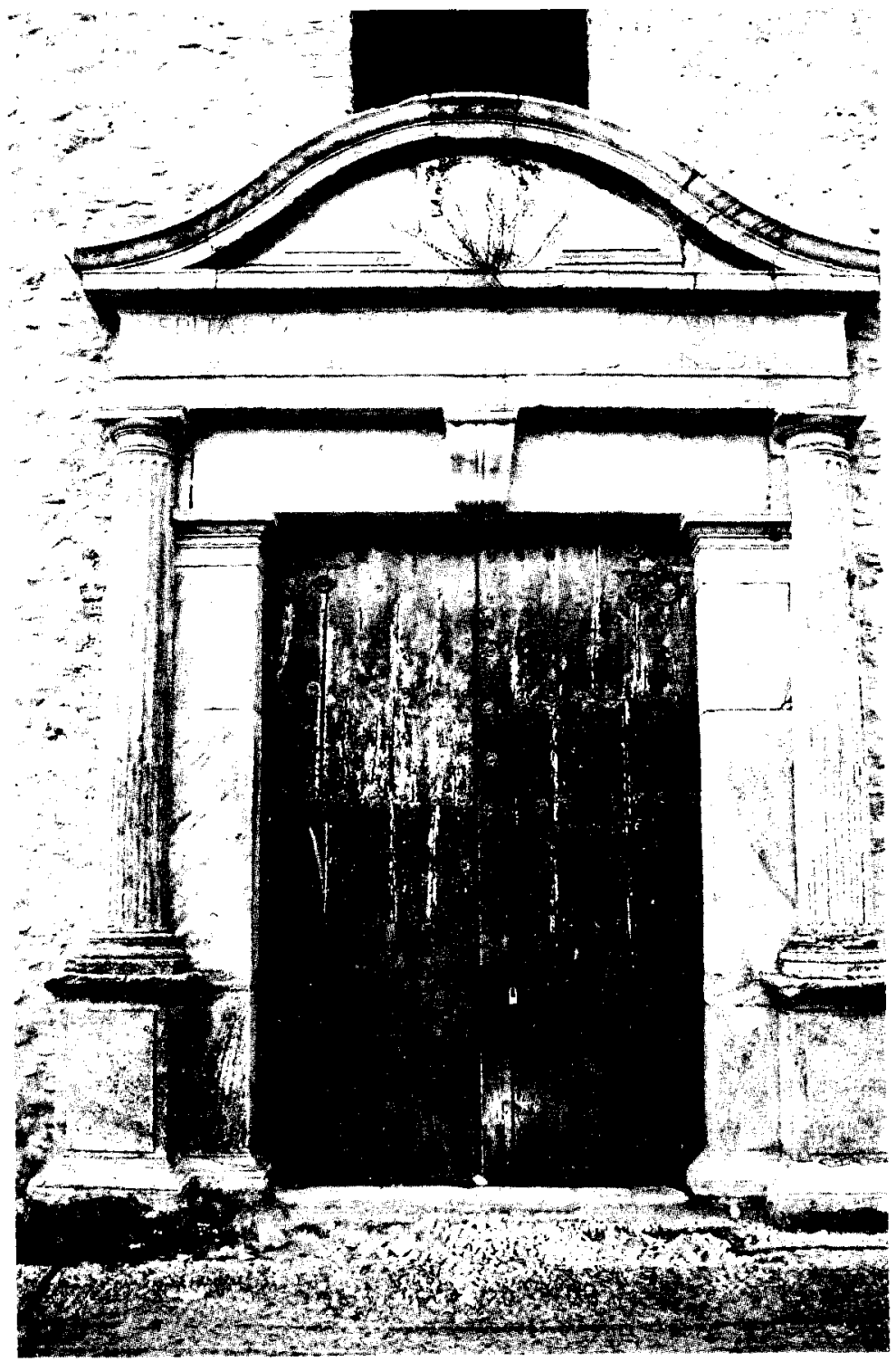

Fig. 5. Hernán Ruiz el Joven. Cabildo Viejo. Aracena (Huelva). 


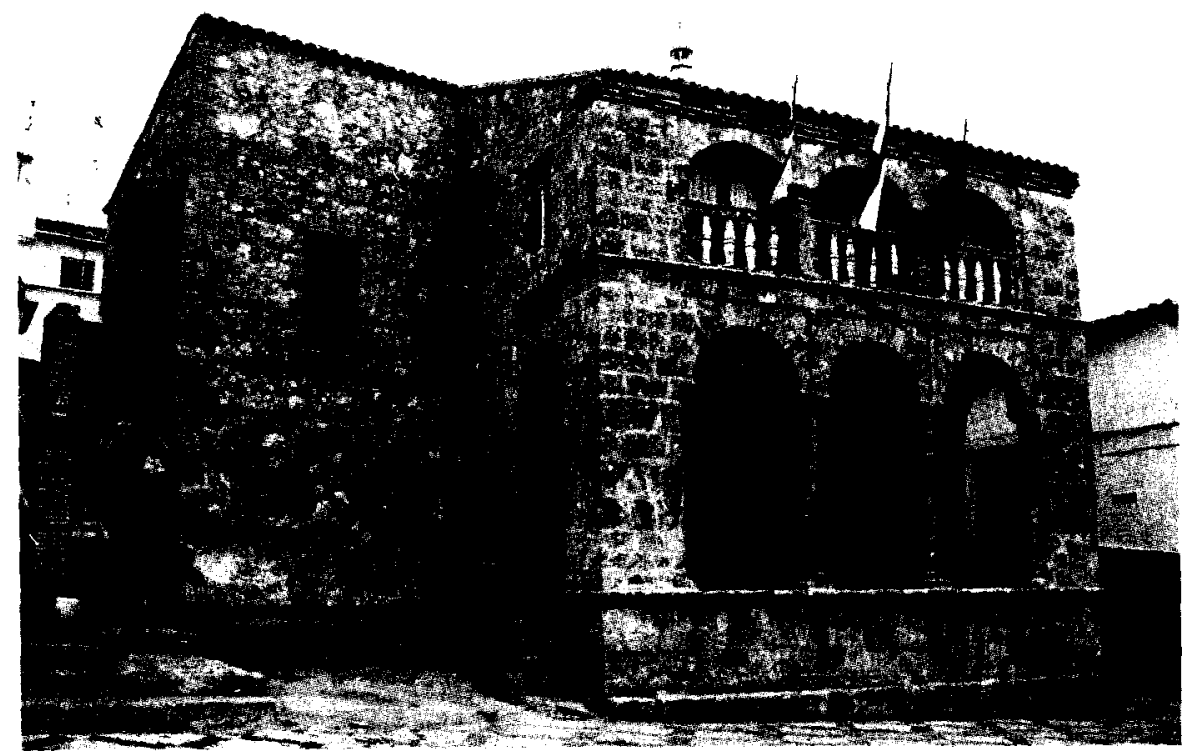

Fig. 6. ¿Hernán Ruiz el Joven? Ayuntamiento. Zufre (Huelva).

apeando sobre pilares toscanos entre los que se desarrolla una balaustrada. El alfiz se repite en una pequeña ventana bífora abierta en el piso alto de la fachada lateral. El ingreso se localiza en un extremo de la galería, estando constituido por un sencillo vano con dintel, de acusado despiece. Al parecer el edificio se estrenó en 1570, lo que hace sospechar que si bien el proyecto inicial se debía a Hernán Ruiz la ejecución material y la dirección de la obra la llevase a cabo alguno de sus colaboradores ${ }^{26}$.

A un lado del cabildo y junto a la escalera que accede a la plaza se colocó el pilar, formado por un sencillo mascarón labrado en la dura caliza de la zona, desde cuyas fauces cae el agua a una reducida taza. Con este elemento se completó el programa de remodelación de la plaza, en la que se dan frente los dos edificios más significativos de la villa, iglesia y ayuntamiento. Sólo la geografía impidió que el resultado de esta ope-

26 La fecha de inauguración es indicada por JIMÉnEz MARTín, Alfonso, "En los márgenes de Hernán Ruiz", Actas del III Congreso Español de Historia del Arte. Resúmenes. Sevilla 1980, pags. 153-155. 
ración urbana fuese más drástico. De hecho, la fábrica del nuevo cabildo y el remozamiento de la iglesia parroquial determinaron que hacia ambos edificios se desplazase toda la actividad vital, configurándose a partir de entonces dicho ámbito como centro del poder civil y religioso (fig. 6).

Asi pues, en Zufre como Aracena y debido a las dimensiones de ambas localidades, se produjo una concentración de funciones, mientras en Sevilla se había producido el fenómeno contrario. A pesar de todo, el recuerdo de la capital estuvo siempre presente en las actuaciones, pues no en vano en todas ellas intervino Hernan Ruiz II. En los tres casos, el arquitecto supo aprovechar la oportunidad que se le brindaba para dotar de una nueva fisonomía a los espacios sobre los que intervenía. En sus planteamientos pudo haber un eco de las recomendaciones vitruvianas que tan bien conocía, pero desde luego nunca la pretensión de llevarlas a la práctica hasta en sus útlimas consecuencias. No obstante, tal y como se dijo al principio, la propia renovación de los edificios públicos, hitos singulares del caserío, y el interés por levantarlos en los bordes de una plaza, vienen a coincidir con los postulados de Vitruvio. 